\title{
SERVIÇOS DE SAÚDE o dilema do SUS na nova década
}

Pedro Luiz Barros Silva

\begin{abstract}
Resumo: A ausência de mecanismos eficazes de regulação e ordenamento da oferta, buscando viabilizar o acesso e a melhor utilização dos serviços do SUS por parte dos usuários, nos níveis macro e microorganizacionais, contribui de forma decisiva para a persistência de problemas relacionados à baixa eficácia do sistema de saúde brasileiro. Este artigo, nos âmbitos, avalia se as reformas introduzidas no setor saúde, no que se refere a cobertura, financiamento, regionalização e gestão, têm contribuído para melhorar o acesso e ampliar a utilização dos serviços de saúde essenciais.

Palavras-chave: reforma do Estado; políticas públicas; política social em saúde.
\end{abstract}

Abstract: The lack of effective mechanisms for regulating SUS services and ensuring their availability at the macro and micro-organizational levels contributes decisively to the persistent ineffectiveness of the Brazilian health care system. This article assesses the degree to which the reforms in the areas of coverage, financing, regionalization and management have contributed to improving access and expanding the utilization of essential health services.

Key words: State reform; public policies; social health policy.

A

reforma do setor saúde esteve muito em moda, no plano internacional, ${ }^{1}$ na década de 90 . A partir de distintos pontos de partida, consolidou-se um conjunto de pressões sobre os governos nacionais para alterar o perfil das políticas públicas setoriais. Entre essas pressões, é possível destacar:

- aumento do nível real de gasto setorial, com forte crescimento do gasto público, exigindo formas mais eficazes de controle governamental;

- convicção entre os gestores públicos e privados de que o tipo de gasto realizado não otimizava o uso dos recursos existentes e disponíveis para o setor;

- possibilidade de expansão do volume de gasto setorial real muito limitada diante tanto das pressões e dificuldades decorrentes dos distintos ajustes nas economias nacionais, quanto do volume já expressivo do gasto setorial em relação ao PIB;

- aumento expressivo da complexidade das condições de oferta e demanda dos serviços;

- problemas, mais ou menos agudos, nas condições de eqüidade no acesso aos serviços por parte dos usuários, especialmente os de menor renda, dependendo da situação nacional em exame;
- problemas generalizados nas condições de escolha dos pacientes determinados pela característica comum dos provedores de serviço em se mostrarem pouco sensíveis aos direitos dos pacientes usuários e consumidores de serviços.

Na base desses fatos comuns aos países ocidentais, tanto na Europa Ocidental quanto nas Américas, evidenciamse três questões de ordem estrutural, presentes com distinta intensidade em cada situação nacional.

A primeira delas envolve as mudanças demográficas, especialmente aquelas decorrentes do envelhecimento da população e do declínio imediato ou futuro da população economicamente ativa, o que determinaria um aumento da demanda por serviços de maior complexidade e custo e tenderia a tornar cada vez mais problemática a capacidade de resposta dos serviços (Eurostat, 2000). Note-se que mesmo em países onde essa transição não impõe um perfil "envelhecido" da população de forma imediata, o simples fato de passar a existir uma população que tende a ser predominantemente adulta pode e vem atuando na mesma direção. Isso ocorre porque também os cuidados médicos tendem a ser mais onerosos quando um grupo populacional adulto está submetido a condições de traba- 
lho e obtenção de rendimentos cada vez mais depauperadoras de suas condições físicas e mentais: transformações das condições de trabalho que tendem a se tornar qualitativamente piores dada a maior flexibilidade e instabilidade dos postos oferecidos; aumento de desemprego aberto, etc. Esse é, sem dúvida, o caso de vários países latino-americanos, com destaque para o Brasil.

A segunda decorre das dificuldades de equacionamento do financiamento e gasto públicos nos quadros de ajustes financeiros macroeconômicos que vêm determinando o corte e a redução da capacidade de intervenção estatal, sem que se tenha delineado com clareza novas e consolidadas formas, comprovadamente eficazes e efetivas, de parceria entre o setor público e o privado, entre os níveis nacionais e subnacionais de governo (no caso de unidades federativas), e entre os níveis central, regional e local de governo (no caso de Estados unitários). Essa questão torna-se mais grave nas situações nacionais localizadas na periferia do sistema financeiro e econômico-produtivo, submetidas a um passado inflacionário desastroso que, a despeito de terem obtido condições de estabilidade da moeda, o fizeram através de estratégias macroeconômicas antagônicas à viabilização de etapas posteriores de desenvolvimento econômico sustentado, dificultando as condições de ajuste do setor público e com custos sociais elevados.

A terceira questão decorre das significativas alterações nas tecnologias disponíveis na área de cuidados médicos (processos, equipamentos e fármacos), alterando o perfil de provisão dos serviços (oferta) com impactos fortes na criação de novas demandas e novas necessidades de financiamento. Nesse sentido, as expectativas dos usuários crescem, convergindo para a exigência de novos padrões de atendimento. De forma diferenciada para cada situação nacional, essas novas exigências parecem refletir um mix envolvendo simultaneamente a oferta de novos serviços, possibilidades de ampliação de acesso a serviços, até então disponíveis para segmentos diferenciados economicamente, e maiores níveis de informação e educação de parcelas da população usuária que passam a exigir tratamentos mais complexos e sofisticados.

Todo esse contexto, aqui delineado de forma bastante genérica, aponta uma tendência convergente de orientação nas modificações das políticas públicas e privadas para o setor. De um lado, países que centravam, de forma quase exclusiva, a organização de serviços nas regras de mercado passam a utilizar instrumentos de planejamento e de regulação, mais visíveis até então nas práticas adminis- trativas do setor público. De outro lado, países com forte tradição de organização estatal dos serviços - ênfase em mecanismos de planejamento, avaliação e controle centralizados - passam a utilizar cada vez mais os instrumentos administrativos e gerenciais, que permitem a introdução de formas administradas de competição no interior do sistema de atenção à saúde, e mecanismos de regulação que diminuem as formas diretas de intervenção do setor público na operação dos serviços.

Com base na literatura disponível para um conjunto significativo de países europeus e americanos, é possível identificar duas importantes lições para o caso brasileiro. Em primeiro lugar, não existe ainda uma tendência consolidada de financiamento e gestão dos sistemas de saúde que permita demonstrar a superioridade de modelos baseados exclusivamente nas regras de mercado ou ao contrário, na intervenção estatal plena. Esse ponto, aparentemente óbvio, deixa de ser no final dos anos 90 uma questão ideológica: a evidência empírica mostra que ainda se buscam intensamente novos instrumentos de política que superem a dicotomia Estado x Mercado e consigam integrar as capacidades públicas (estatais e não-estatais) e privadas de forma sinérgica, o que ainda não foi obtido com pleno sucesso por nenhuma experiência nacional.

Em segundo lugar, que o "coração das reformas" está ligado, no plano geral, a modificações, tanto no nível macro quanto no nível micro, das formas de financiamento dos sistemas e das suas formas de organização, gestão e regulação, o que inclui modificações importantes em certos pressupostos do modelo assistencial adotado. A maior probabilidade de sucesso na empreitada está ligada tanto à escolha das modificações em cada campo - financiamento e gestão - quanto às possibilidades de combinar sinergicamente seus resultados, criando bases políticas, institucionais e societais de sustentabilidade das transformações introduzidas.

\section{CARACTERÍSTICAS COMUNS DOS PROCESSOS DE REFORMA NOS PAÍSES EUROPEUS E NORTE-AMERICANOS}

A partir da segunda metade dos anos 80, combinaramse e foram estimuladas políticas diferenciadas de intervenção procurando alterar condições de operação dos sistemas nacionais, nos planos macro e microorganizacionais.

No que diz respeito ao macrofuncionamento dos sistemas de saúde, foram adotadas predominantemente fórmulas para obter a contenção de custos e para definir uma 
política de transferências do nível central de governo para instâncias descentralizadas ou subnacionais, conforme cada caso, que favorecesse tal processo. Esse tipo de decisão decorre do exame do funcionamento e desempenho das três formas básicas para as quais convergem os distintos mecanismos de financiamento dos sistemas de atenção à saúde: financiamento público baseado em impostos; financiamento público baseado em contribuições compulsórias da previdência social; finalmente, o financiamento privado baseado em seguros específicos para a atenção à saúde (Maxwell, 1988). Nesse sentido, a experiência internacional tem demonstrado maiores deficiências no desempenho dos sistemas de financiamento de bases voluntárias controlados por regras tipicamente de mercado (incerteza e risco desse tipo de seguro; existência de "risco moral" afetando tanto o comportamento de usuários e provedores de serviço - sobreutilização associada ao uso impróprio de equipamentos e terapias; incentivos à seleção adversa de pacientes; maiores dificuldades para obter coberturas universalizadas e acesso equânime; altos custos administrativos). De outro lado, sistemas financiados por impostos ou por contribuições compulsórias, embora relativamente bem-sucedidos no processo de contenção de custos - através da utilização de orçamentos globais com base prospectiva para hospitais; controles centrais para a construção de instalações e aquisição de equipamentos; limitações nas remunerações das equipes médicas e sua padronização; tabelas padronizadas de remuneração de procedimentos; restrições no processo de formação de profissionais, etc. -, enfrentaram problemas no campo da qualidade dos serviços, na produtividade obtida e na excessiva burocratização e centralização de procedimentos e controles, acarretando custos administrativos também bastante elevados.

Esse processo de "aprendizado institucional" dos diferentes sistemas determinou uma alteração estrutural de modelos privatizados e públicos (estes últimos também conhecidos como modelos integrados de financiamento e provisão de serviços) para modelos contratuais integrados, a partir de bases de mercado (caso americano) ou bases públicas (caso europeu de forma geral).

Com isso, alteram-se de forma ainda mais significativa as condições microorganizacionais de funcionamento dos sistemas de atenção em que se procurou combinar: iniciativas para aumento da eficiência e melhora da resolutividade da rede de serviços, através da separação de provedores e financiadores como mecanismo de introdução de competição administrada (ou quase mercados) no interior desse novo modelo contratual; reforço e melhoria das condições internas de gestão das unidades prestadoras de serviço em todos os níveis de atendimento, buscando-se minimizar variações de desempenho e introduzir uma nova cultura organizacional na qual se possa ampliar o poder de escolha dos pacientes, melhorar as condições de acesso, reduzir os tempos de espera nas listas de cuidados eletivos, aumentar a qualidade da prestação de serviços.

As modificações dos níveis macro e micro quando combinadas envolveram:

- intenso investimento e melhoria dos sistemas de informação voltados à decisão gerencial, possibilitando um fluxo ágil e efetivo de dados acerca das principais transações realizadas pelo sistema e por suas unidades;

- programas de capacitação em gestão para médicos, enfermeiros e outros profissionais da equipe de saúde;

- aumento dos graus de responsabilidade e autonomia decisória dos gestores do sistema nos níveis regionais e periféricos, nas unidades prestadoras de todos os tipos e no interior dessas mesmas unidades;

- terceirização de todas as atividades em que, comprovadamente, o setor privado possua maior competência;

- contratação de gestores profissionais para atividades de gerenciamento dos sistemas ou de suas unidades hospitalares, ambulatoriais ou de atenção primária;

- adoção de "pacotes" de incentivos, incluindo incentivos salariais, visando a obtenção de resultados mais eficazes e efetivos, seja no plano macro seja no plano microorganizacional;

- utilização de mecanismos e incentivos orçamentários e financeiros como meio de aumentar o desempenho dos sistemas e adequar a oferta dos serviços às necessidades da população-alvo.

\section{ANTECEDENTES DA POLÍTICA DE ATENÇÃO À SAÚDE NO BRASIL}

Como já é conhecido, o Sistema Único de Saúde (SUS), estabelecido pela Constituição Federal de 1998, ao induzir o processo de descentralização da atenção sanitária, buscou implantar um modelo assistencial que revertesse o perfil de intervenção governamental nesse setor. Ao final dos anos 80 a política de atenção à saúde era marcada pela ineficiência da gestão pública e pela baixa efetividade das ações no atendimento das necessidades da população. 
A partir de 1988, foi consolidada e formalizada na Carta Constitucional uma tendência de reconhecimento da atenção à saúde como um direito social, processo que se inicia no princípio dos anos 80 . A Constituição buscou, explicitamente, assegurar o acesso universal e igualitário sem restrições e discriminações derivadas de posições diferenciadas na heterogênea e complexa estrutura social brasileira - às ações (políticas e programas) e serviços de promoção, proteção e prevenção da saúde. ${ }^{2}$

Tal definição constitucional, para que fosse viabilizada de fato, envolvia a definição e implantação de uma estrutura de atenção que abrangesse todos os brasileiros e operasse dentro dos princípios de máxima eqüidade, alterando, conseqüentemente, as principais características do perfil de política de atenção à saúde, forjado durante a situação autoritária que vigorou no país por três décadas e prevaleceu no Brasil até meados dos anos $80 .^{3}$ Dentre essas características merecem destaque neste trabalho:

- a forte centralização na esfera federal de governo e, dentro dela, no Instituto Nacional de Assistência Médica da Previdência Social - Inamps, autarquia vinculada ao Sistema Nacional de Previdência e Assistência Social Sinpas - que ao comandar o processo do gasto público setorial viabilizou por décadas ações e serviços de assistência médica de base hospitalar, bastante dissociados de ações integradas de promoção, prevenção e proteção da saúde;

- a fragmentação organizacional, o que impossibilitava a implementação de uma política setorial integrada ao promover, principalmente, a dicotomia entre as ações no âmbito do Ministério da Saúde, das Secretarias Estaduais de Saúde e, finalmente, das Secretarias Municipais, de um lado; e do Inamps e dos prestadores de serviços de assistência médica - ambulatorial ou hospitalar - privados ou públicos não-governamentais (entidades filantrópicas) contratados ou conveniados com essa autarquia, de outro. Configurou-se, assim, uma estrutura de prestação de serviços constituída de seis segmentos: o segmento previdenciário, envolvendo estabelecimentos próprios do Inamps (postos de assistência médica e hospitais de médio e grande portes) e estabelecimentos privados; o segmento médico sanitário vinculado ao Ministério da Saúde que, para implementar diversos programas de abrangência nacional, mantinha uma rede própria de unidades ambulatoriais e hospitalares para combate ao câncer, atendimento psiquiátrico, dermatologia sanitária, tuberculose, atenção materno-infantil, etc., além da rede da Fundação Serviço Especial de Saúde Pública - Sesp encarregada da prestação de serviços de assistência médica e de saneamento básico nas regiões mais distantes e pobres do país; o segmento de hospitais universitários, vinculado ao Ministério da Educação, que fazem, ainda hoje, parte das Universidades Federais existentes em cada Estado da Federação Brasileira, mantendo, além de suas atividades de ensino e pesquisa, serviços de magnitude e complexidade diferenciados de atenção médica à população em regime universal, na maior parte em convênio com o Inamps; o segmento das Forças Armadas e do funcionalismo público (nos diferentes níveis de governo) que também mantém uma rede própria de hospitais e ambulatórios; o segmento estadual e municipal de atenção médico-hospitalar e de saúde pública, composto de unidades básicas de saúde (centros e postos de saúde) e de unidades de emergência nos Estados e municípios de maior porte e condição econômica; finalmente, um segmento privado autônomo voltado às camadas da população com alto poder aquisitivo ${ }^{4}$ ou articulado a partir da necessidade das empresas de maior porte e complexidade (medicinas de grupo, cooperativas médicas, seguradoras do ramo saúde, serviços de autogestão médica das empresas), que cresce dinamicamente no vácuo possibilitado pelas deficiências da política de assistência médica previdenciária e de atenção médicosanitária proporcionada pelos Estados e municípios;

- a ausência de mecanismos de controle público e social, tanto no que diz respeito ao processo mais geral de definição de formas de financiamento, prioridades alocativas e distribuição geográfica dos serviços, quanto no que se refere ao controle social da qualidade e do tipo de serviço prestado aos usuários;

- a forte concentração do atendimento nas unidades hospitalares ou no atendimento ambulatorial de nível secundário, o que é explicável pela, já citada, predominância da política de assistência médica previdenciária e de seus recursos financeiros, infinitamente superiores em capacidade de atendimento e de gasto às estruturas de saúde voltadas à promoção e prevenção da doença. Isso implicou a estruturação de uma rede de atendimento atuando sem hierarquia, implantada sem que fossem considerados os critérios de regionalização, sistemas de referência e mecanismos de integração, complementaridade e coordenação do atendimento.

Esse perfil de intervenção viabilizou uma política de atenção à saúde com inegável tendência de expansão da cobertura e do gasto - ainda que em níveis inferiores aos observados, naquele momento, em países da América 
Latina com graus semelhantes de desenvolvimento - apoiada, como já foi apontado, em uma rede de prestação de serviços desordenada e desarticulada, dada a inexistência de mecanismos de planejamento e gestão que viabilizassem o seu funcionamento de forma regionalizada, hierarquizada e resolutiva.

A estruturação de um sistema único de saúde procurou ampliar os níveis de responsabilidade da gestão local e regional para solucionar, simultaneamente, questões referentes à melhora da eficácia do gasto público e à ampliação do acesso aos serviços. Como aponta, corretamente, Médici (1999), a implantação do SUS teve como principal justificativa a necessidade de melhorar a oferta de serviços, os indicadores de saúde e as condições de acesso, contribuindo para elevar a qualidade de vida da população brasileira. Mais de dez anos após o início desse processo e a despeito de avanços inequívocos tanto dos indicadores de saúde quanto da eficiência do atendimento em diversos Estados e municípios brasileiros, verifica-se que o Brasil ainda apresenta padrões de morbidade e mortalidade precários. A realidade sanitária brasileira revela padrões que mesclam distintas etapas do processo de transição epidemiológica, combinando a presença de doenças verificadas em sociedades pré-industriais, industriais e pósindustriais. Em parte, essa realidade é resultante da permanência de problemas de cobertura assistencial, financiamento setorial, resolutividade sistêmica e eqüidade no acesso e na utilização dos serviços.

\section{ANOS 80: A SITUAÇÃO PRÉ-SUS}

A política de atenção à saúde no Brasil foi financiada basicamente com recursos do Fundo de Previdência e Assistência Social (FPAS) até 1990. A análise da evolução dos gastos com atenção à saúde nas três esferas de governo entre 1980 e 1990 mostra que a participação da União nunca é inferior a $71 \%$ (1986), tendo alcançado o patamar de $87 \%$ aproximadamente em 1988.

Analisando-se a seguir a evolução do gasto federal por fonte de financiamento, verifica-se que a participação dos recursos previdenciários na manutenção da política de atenção à saúde através do FPAS foi, no mesmo período, sempre superior a 76\% (1986), alcançando seu maior patamar de participação no início da década de 80 .

A despeito de crescerem 9,5\% entre 1980 e 1990, os dispêndios per capita em atenção à saúde ainda se situavam em um patamar baixo, configurando uma situação que já virou "palavra de ordem" entre os militantes do setor: o segmento público da saúde no Brasil gastou pouco.

Considerando-se esse gasto em relação ao PIB, apresentado na Tabela 1, e comparando essas informações com os dados apresentados pelo relatório do Banco Mundial de 1993, dedicado ao setor saúde, nota-se que essa participação é bastante inferior à participação média setorial nos países das economias capitalistas centrais (OCDE), que se situavam em torno de 5,6\% do PIB médio.

Mas se for considerado o gasto total em saúde, estimado por Médici (1999) para o ano de 1989, a situação se transforma um pouco. Em tal estimativa, o gasto total público nas três esferas de governo e privado autônomo (famílias seguradas mais gastos familiares diretos e gasto das empresas com seguros-saúde e assemelhados para seus empregados) - em relação ao PIB chega a 4,66\%.

Ou seja, bastante próximo dos 5,6\% dos países do centro capitalista, onde o gasto privado é muito menor, e significativamente maior do que a média dos países da América Latina, excetuando-se o Chile, dentre os países onde a comparação possa fazer sentido para a argumentação aqui desenvolvida. Os países da OCDE e a maioria dos países latino-americanos apresentam, entretanto, indicadores de saúde superiores aos brasileiros. Como apontam Barros, Piola e Vianna (1996:13), "tem sido fartamente documentada a situação paradoxal do Brasil de apresentar indicadores econômicos em níveis incompatíveis com os dos indicadores sociais, incluindo-se os de saúde". Mesmo

TABELA 1

Evolução dos Gastos com Saúde em Relação ao PIB Brasil - 1980-90

\begin{tabular}{llccc}
\hline Anos & Total & União & Estados & Municípios \\
\hline 1980 & 2,34 & 1,75 & 0,42 & 0,17 \\
1981 & 2,36 & 1,74 & 0,44 & 0,18 \\
1982 & 2,37 & 1,75 & 0,41 & 0,20 \\
1983 & 2,14 & 1,55 & 0,41 & 0,18 \\
1984 & 2,15 & 1,60 & 0,39 & 0,16 \\
1985 & 2,23 & 1,60 & 0,42 & 0,21 \\
1986 & 2,27 & 1,56 & 0,47 & 0,24 \\
1987 & 2,81 & 2,33 & 0,25 & 0,23 \\
1988 & 2,69 & 2,31 & 0,00 & 0,38 \\
1989 & 3,26 & 2,52 & 0,38 & 0,36 \\
1990 & 3,19 & 2,32 & 0,49 & 0,38 \\
\hline
\end{tabular}

Fonte: Ipea (1992); Médici (1993). 
levando-se em conta que na década de 80 ocorreu uma melhora de vários indicadores, a velocidade dessa melhora não foi suficiente para eliminar a desigualdade entre o Brasil e outros países da América Latina.

Isso coloca ao analista uma questão mais complexa: o problema estratégico do SUS, tanto quanto elevar o patamar do gasto, foi e continua sendo imprimir a esse gasto maior efetividade. Isso só se consegue com o planejamento da oferta de serviços induzindo a direção das ações para as necessidades prioritárias da população, simultaneamente ao ordenamento do acesso e da utilização dos serviços através de uma rede corretamente regionalizada, hierarquizada e resolutiva.

Parte significativa da explicação da baixa efetividade do gasto em saúde diz respeito, portanto, à ênfase da política de atenção à saúde até o início dos anos 90. Como já foi apontado, essa ênfase recaiu sobre as ações curativas, baseadas na atenção hospitalar com custos crescendo de forma exponencial, no interior de uma rede de serviços desarticulada e mal hierarquizada, sem mecanismos resolutivos de ordenamento tanto da oferta quanto da demanda de serviços, sem priorizar os serviços de promoção da saúde e prevenção da doença (Médici, 1999; Barros et al., 1996; Banco Mundial, 1993; Silva, 1984 ,1992, entre outros).

Mais do que isso, há fortes diferenciais de acesso por níveis de renda da população, evidenciando que as famílias de menor renda são penalizadas tendo menor possibilidade de utilizar a rede de serviços. Problemas de distância dos equipamentos de atenção à saúde; falta de recursos para custear as despesas de transporte; exigências de pagamento de consultas e de medicamentos (o conhecido pagamento "por fora") - ainda que formalmente já vigorasse, desde 1983, o princípio da gratuidade e da universalidade; ausência de acesso a informações que permitissem às famílias mais pobres entender a necessidade de utilizar os equipamentos de saúde disponíveis a partir da ocorrência de determinados sintomas de enfermidade; foram as causas mais relevantes identificadas a partir de pesquisa nacional sobre a temática (PNAD, 1986 - suplemento saúde). É bem verdade que, desde meados dos anos 80 , começam a se estruturar iniciativas que procuram modificar esse perfil de intervenção. As tentativas de mudança concretizadas através do Programa de Interiorização das Ações de Saúde e Saneamento (Piass), das Ações Integradas de Saúde (AIS) e mais decisivamente através da implantação do Sistema Unificado e Descentralizado de Saúde (Suds), refletem claramente a evolu- ção desse processo (Silva, 1992; Levcovitz, 1997; Médici, 1999). Entretanto, não foram suficientes para alterar o dramático perfil de iniqüidades que a política de atenção à saúde apresenta nesse período.

Utilizando a informação disponível de abrangência nacional, para a década de 80 , acerca das taxas de utilização dos serviços de saúde por nível de renda mensal familiar per capita, Médici (1999) aponta que as famílias com renda superior a dois salários mínimos utilizam os serviços de saúde numa proporção $60 \%$ maior do que as famílias com renda per capita até $1 / 4$ de salário mínimo (Tabela 2). Indica ainda que as más condições de acesso e a falta ou pouco apropriada percepção do processo de saúde - enfermidade, decorrente das falhas nas ações de promoção da saúde e prevenção da doença entre os estratos de mais baixa renda - são determinantes fundamentais dessa situação.

Mais significativo é o fato identificado, ao final dos anos 80 , de que as famílias de renda mais baixa gastaram proporcionalmente mais com serviços de saúde do que as com renda mais alta. Isso ocorria por duas razões fundamentais: os serviços disponíveis, ainda que formalmente gratuitos desde 1983, como apontado acima, não o eram para $16 \%$ das famílias com renda per capita até $1 / 4$ de salário mínimo que declararam pagar pelo atendimento recebido, ${ }^{5}$ as famílias de baixa renda têm um gasto com saúde proporcionalmente mais alto porque, a despeito de utilizar menos os serviços dadas as piores condições de acesso, quando o fazem necessitam de cuidados relacionados com ocorrências de maior gravidade e risco, portanto mais caras.

\section{TABELA 2}

Taxas de Utilização dos Serviços de Saúde, segundo Classes de Renda Mensal Familiar per Capita

Brasil - 1986

Em porcentagem

\begin{tabular}{lcc}
\hline $\begin{array}{l}\text { Classes de Renda } \\
\text { Familiar per Capita } \\
\text { (em salários mínimos) }\end{array}$ & $\begin{array}{c}\text { Distribuição da } \\
\text { População }\end{array}$ & $\begin{array}{c}\text { Taxa de Utilização dos } \\
\text { Serviços de Saúde (1) }\end{array}$ \\
\hline Total (2) & 100,0 & 11,0 \\
Até $1 / 4$ (3) & 14,2 & 8,6 \\
De $1 / 4$ a $1 / 2$ & 19,4 & 9,3 \\
De $1 / 2$ a 1 & 25,0 & 10,7 \\
De 1 a 2 & 21,5 & 11,6 \\
Mais de 2 & 15,9 & 13,8 \\
\hline
\end{tabular}

Fonte: PNAD 1986. In: Médici (1999).

(1) Definida como a relação entre a população que utilizou serviços de saúde e a população total em cada classe de renda considerada no mês da pesquisa (setembro de 1986).

(2) Exclui as famílias sem declaração de rendimentos.

(3) Incluiu $1 \%$ de pessoas pertencentes a famílias sem rendimento. 
TABELA 3

Taxas de Utilização dos Serviços de Saúde, por Nível de Renda Mensal Familiar per Capita, segundo Motivos de Procura pelo Serviço Brasil - 1986

\begin{tabular}{lcc}
\hline $\begin{array}{l}\text { Motivos de Procura } \\
\text { pelo Serviço de Saúde }\end{array}$ & $\begin{array}{c}\text { Até } 1 / 4 \text { de } \\
\text { Salário Mínimo }\end{array}$ & $\begin{array}{c}\text { Mais de 2 } \\
\text { Salários Mínimos }\end{array}$ \\
\hline Total & 100,0 & 100,0 \\
Doença & 85,6 & 64,5 \\
Acidente ou Lesão & 5,1 & 5,1 \\
Problema Odontológico & 2,5 & 7,3 \\
Controle ou Prevenção & 4,6 & 18,9 \\
Outros Motivos (1) & 2,1 & 4,1 \\
Sem Declaração & 0,1 & 0,1 \\
\hline
\end{tabular}

Fonte: PNAD 1986. In: Médici (1999).

(1) Incluem obtenção de carteira de saúde, tratamento de reabilitação, psicanálise, etc.

A Tabela 3 apresenta os motivos que levam as famílias, estratificadas por nível de renda, a procurar os serviços de atenção à saúde identificados pela PNAD de 1986.

Nota-se também que as famílias de renda maior do que 2 salários mínimos gastam mais em prevenção, demonstrando uma percepção sanitária mais adequada e melhores condições de acesso decorrentes de sua melhor condição socioeconômica. Esses fatores são decisivos para que se observem, nesse período, diferenciais significativos de longevidade, decorrentes em última instância de hábitos de vida que demonstram o exercício mais completo de condições de cidadania e que não são disponíveis para as famílias de renda mais baixa. Para essas se concretizou o "pior dos mundos": menor acesso aos serviços e à informação e educação sanitária, associado a piores condições de vida. Isso se reflete com clareza no perfil de morbidade e mortalidade que assola essa parcela da população - simultânea incidência de doenças infecto-contagiosas e de doenças crônico-degenerativas acompanhadas, no início dos anos 90, das chamadas doenças da sociedade pósmoderna como a Aids.

Partindo de informações constantes da amostra da Pesquisa Nacional de Saúde e Nutrição (PNSN) também realizada pela Fundação IBGE, em 1989, Travassos, Fernandes e Pérez (1989) chegam a conclusões semelhantes: "Esses resultados mostram grande seletividade social no consumo dos serviços de saúde, com os grupos sociais tendo acesso diferenciado aos vários subsistemas (ou como chamamos neste trabalho segmentos - PLBS) que operavam com padrões de qualidade e eficiência marcadamente distintos: aos mais pobres, menor oferta de serviços, po- larizada entre o atendimento básico e o pronto-socorro/ hospital; aos mais ricos, maior oferta de serviços, mais diferenciada em complexidade tecnológica, com ênfase no atendimento preventivo e ambulatorial".

Esse estudo explicita, ainda, um outro aspecto extremamente importante para a nossa argumentação: observou-se que a composição do consumo de serviços de saúde entre os grupos de renda distinta está marcada pela utilização efetiva do consultório particular ou privado na medida em que aumenta a renda. Como apontam os autores, é o consultório particular que marca a passagem do mercado de serviços de pobres para o dos ricos. Em outras palavras, os ricos têm acesso a cuidados de promoção, prevenção e cura de forma mais hierarquizada e resolutiva, porque o consultório particular funciona adequadamente como porta de entrada do sistema e unidade de referenciamento para cuidados mais complexos, no setor público ou no setor privado, quando necessário. Esse mecanismo depende de disponibilidade de recursos financeiros ou emprego formal em organizações que proporcionem alguma forma de cobertura em atenção à saúde para seus empregados. Aos pobres, excluídos dessa realidade, resta o pronto-atendimento hospitalar público, com fortes restrições de acesso a partir daí, e a farmácia. ${ }^{6}$

Note-se, entretanto, que quando se conseguiam romper as barreiras de acesso aos ambulatórios e hospitais públicos, nesse momento majoritariamente ligados à Previdência Social ou Hospitais Universitários, o grau de satisfação dos usuários, especialmente os de menor renda, aumentava significativamente. Pesquisa realizada pelo Instituto Vox Populi em julho de 1987, entre usuários efetivos dos serviços do Inamps, mostrou que, à medida que se aprofundava a relação do usuário com o serviço, as avaliações iam ficando consistentemente positivas. Segundo essa pesquisa: “[...] para 46,6\% de aprovação com o primeiro médico da triagem, passamos para $64,8 \%$ das consultas com especialistas e saltamos para uma aprovação de 75,3\% nas internações. Quando chegamos às pessoas que passaram por eles, que são as que percorreram o caminho inteiro de sua relação com os serviços de assistência médica da previdência social, alcançamos os mais altos índices de aprovação do atendimento, além do patamar dos três quartos" (Vox Populi, 1987).

Ainda que, em saúde, a percepção dos usuários não seja sempre um indicativo da resolutividade e eficácia do serviço, o que chama a atenção e reforça a argumentação é que, para o usuário, ter a possibilidade de utilizar o serviço ao longo de toda a rede de atendimento é um ganho real. E nesse caso valorizando o serviço público. 


\section{DEZ ANOS DE IMPLEMENTAÇÃO DO SUS: MECANISMOS DE ORDENAMENTO E CONDIÇÕES DE ACESSO AO FINAL DOS ANOS 90}

Mais de dez anos após o início do processo de implementação de um sistema único de saúde no Brasil, nota-se que a atenção à saúde continua sendo operacionalizada através de um sistema segmentado e desarticulado.

A rede operada através do SUS, comandada pelo setor público através de um conjunto de normas operacionais em que se definem formas de financiamento e atribuições e competências de cada nível de governo, utilizando-se de prestadores públicos e privados de serviço e destinados a proporcionar, de forma gratuita e universal, cobertura a toda a população brasileira. Estimativas indicam que o SUS teoricamente estaria atendendo, atualmente, de forma exclusiva, 114,6 milhões de pessoas. $^{7}$

Um segmento de medicina supletiva ao SUS (SMS) tem cobertura estimada de 45 milhões de pessoas, operando através de planos de saúde contratados pelos indivíduos ou por empresas, em organizações de medicina de grupo, cooperativas médicas, seguradoras do ramo saúde e planos auto-administrados, nos quais se incluem os empregados das empresas estatais e privadas de grande porte.

Um segmento de prestadores de serviço que é remunerado através do desembolso direto de seus usuários (SDU) e abrange, teoricamente, a população com mais alto poder aquisitivo.

A despeito dessa multiplicidade de formas de atendimento, estima-se que uma parte ponderável da população, em torno de $10 \%$ das pessoas, esteja à margem até do atendimento prestado pelo SUS. Isso significa que cerca de 16 milhões de pessoas estejam sem acesso a nenhum serviço, podendo-se concluir que, de forma exclusiva, o SUS deve cobrir cerca de 99 milhões de brasileiros.

Como é conhecido pelos estudiosos do setor, é difícil apontar com exatidão a magnitude da clientela de cada um desses segmentos, pois não existem barreiras que coíbam a utilização dos serviços do SUS pelos indivíduos inseridos no SMS ou que podem ser classificados como do SDU, dadas a gratuidade e universalidade que regem a operação deste último. Note-se que a situação inversa não é verdadeira pois a condição socioeconômica continua sendo uma barreira intransponível para aqueles que, estando no SUS, queiram utilizar os serviços dos outros segmentos. Mais do que isso, como para determinados procedimentos os prestadores de serviço realizam atendimento para o SUS e para o SMS, estratégias de utilização indiscriminada de pessoas e de empresas dos serviços do SUS acontecem cotidianamente. Não é possível aferir sua necessidade ou promover a compensação ao SUS, de cobertura ampla e irrestrita teoricamente, dos custos ocorridos para o atendimento de pessoas que se utilizam e pagam preferencialmente os outros segmentos.

Pesquisa do Ibope ${ }^{8}$ realizada em 1998 por encomenda do Conselho Nacional de Secretários Estaduais de Saúde - Conass e da Fundação Nacional de Saúde - FNS do Ministério da Saúde, mostra que a cobertura real do SUS pode ser ainda menor do que os estimados 99 milhões de brasileiros. Essa pesquisa mostra que:

- 38\% da população afirmou utilizar de forma exclusiva os serviços públicos ou com ele conveniados;

- 20\% declarou utilizar o SUS de forma freqüente (maioria das vezes), mas não exclusiva;

- 22\% declarou utilizar serviços particulares na maioria das vezes, utilizando tanto os serviços públicos (eventuais) como os do segmento supletivo;

- 15\% da população declarou não ser usuária do SUS, seja por pertencer ao segmento que utiliza exclusivamente serviços particulares (via seguro-saúde de qualquer espécie ou via desembolso direto) ou por nunca utilizar serviço médico de qualquer espécie.

Já existem indicações bastante significativas para mostrar que os segmentos populacionais de menor nível de renda, menor escolaridade, situados em regiões que concentram grupos de grande vulnerabilidade social, como, por exemplo, periferias de áreas metropolitanas, municípios médios com atividade industrial decadente ou municípios pequenos de vocação agrícola fora da dinâmica competitiva dos mercados agroindustriais) não se utilizam do SUS por falta de condições de acesso determinadas por motivos diversos (Médici, 2001).

Verifica-se também que quanto mais aumentam a escolaridade e a renda, menor é o grau de utilização intensiva do SUS, confirmando que o acesso para as camadas mais pobres é essencial e estratégico.

Mas o mais interessante é a evidência de uma tendência de utilização dos serviços do SUS por camadas com alta escolaridade e maior poder aquisitivo: mais de 50\% daqueles que têm escolaridade superior e mais de $60 \%$ das que recebem rendimentos superiores a 10 salários mínimos.

Isso pode indicar duas situações. Na primeira, em decorrência de uma estrutura de atenção segmentada, nãohierarquizada, com má-distribuição regional e pouco 
resolutiva, ocorreria que uma parte significativa das pessoas com maior poder aquisitivo, maior escolaridade e, portanto, maiores chances de pertencer ao mercado formal de trabalho em postos de qualidade, tenha acesso a esquemas de seguro-saúde e simultaneamente se utilize do sistema SUS. Isso caracterizaria uma ação oportunista por parte dos usuários, legal é verdade, dadas as brechas permitidas pelo sistema que beneficiariam os segmentos mais protegidos por sua melhor condição socioeconômica e buscariam no SUS o cuidado de mais alto custo e maior complexidade. Em decorrência, estariam consumindo parte dos recursos que poderiam estar sendo mais bem utilizados se o sistema fosse corretamente regulado e ordenado do ponto de vista do acesso, para minimizar esse comportamento oportunista verificado.

Os dados acerca da evolução da clientela e do faturamento do segmento de medicina supletiva no Brasil, nos dez anos de existência do SUS, mostram uma dinâmica e um volume de recursos envolvidos impressionantes, que podem ser vistos na Tabela 4.

Na segunda situação, em decorrência da desestruturação do mercado de trabalho e do desemprego, segmentos de maior renda estariam utilizando mais o SUS em decorrência da perda do poder aquisitivo e da possibilidade que o acesso universal e gratuito dá a esses segmentos de obter ou um rebaixamento de seus custos privados com atenção à saúde ou não mais realizá-los. Note-se que a mesma pesquisa Ibope mostra que quando perguntado sobre os três maiores problemas que o entrevistado e sua família vinham enfrentando, $48 \%$ indicou o desemprego, 37\%, o nível salarial e 37\%, a saúde (respostas múltiplas).

\section{TABELA 4}

Clientela e Faturamento do Setor de Medicina Supletiva Brasil - 1989-1998

\begin{tabular}{lccc}
\hline Anos & $\begin{array}{c}\text { Número de Usuários } \\
\text { (em milhões) }\end{array}$ & $\begin{array}{c}\text { Faturamento } \\
\text { (em US\$ bilhões) }\end{array}$ & $\begin{array}{c}\text { Gastos per Capita } \\
\text { (em US\$) }\end{array}$ \\
\hline 1989 & 31,1 & 2,4 & 77,70 \\
1991 & 28,5 & 4,1 & 146,30 \\
1993 & 34,4 & 6,4 & 187,80 \\
1995 & 37,5 & 9,9 & 264,00 \\
1996 & 39,2 & 12,3 & 313,57 \\
1997 & 41,0 & 15,3 & 373,50 \\
1998 & 45,0 & 16,0 & 357,77 \\
\hline
\end{tabular}

Fonte: Mendes (1998).
Em qualquer dos casos, fica evidente que há um desperdício de recursos, acompanhado por barreiras concretas de acesso, que permitem a utilização de estratégias oportunistas ou "desesperadas" por parte da população e decorrem do que se pode chamar uma segmentação permissiva e incestuosa das redes de atendimento determinada pela falta de ordenamento, multiplicidade de coberturas, baixa resolutividade e falta de planejamento, coordenação e regulação da atenção à saúde no Brasil.

Daí resultam várias distorções no campo do financiamento, do gasto público e privado e, finalmente, na utilização dos serviços, que serão examinadas nas seções seguintes deste trabalho.

\section{FINANCIAMENTO E GASTO DO SUS}

A implantação do SUS enfrenta, nesse campo, obstáculos complexos, o que vem determinando a polarização de posições no debate político institucional em torno da questão da suficiência ou insuficiência de recursos para sustentar uma política eficaz de intervenção.

A primeira observação importante a ser feita é que foram significativamente modificadas as fontes de financiamento. A despeito das flutuações e da turbulência financeira que o setor atravessa, como mostra o Gráfico 1 que retrata 18 anos de evolução do gasto federal com saúde e a sua expressão per capita, nota-se a partir de 1993 uma tendência de crescimento contínuo. ${ }^{9}$

\section{GRÁFICO 1}

Evolução do Gasto Federal com Saúde e do Gasto per Capita com Saúde Brasil-1980-98

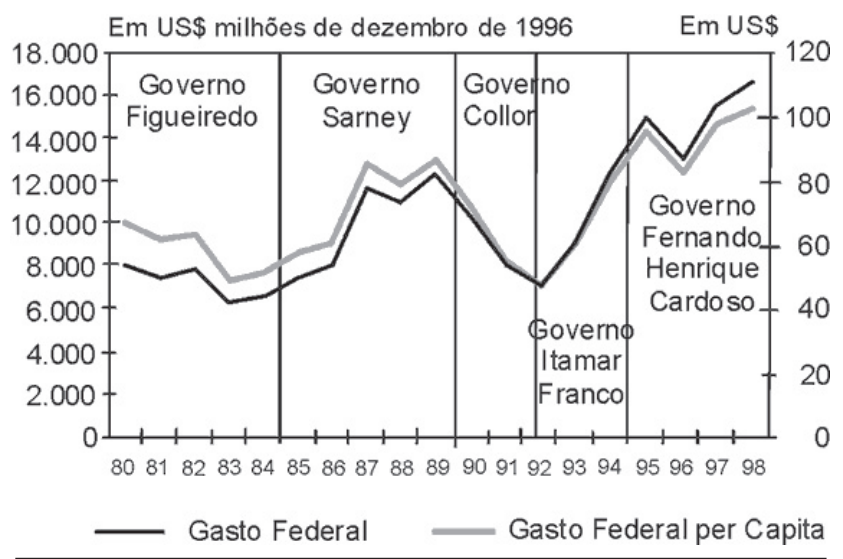

Fonte: Médici, 1999. 
Em 1995, contabilizando-se o gasto realizado nas três esferas de governo, chega-se a um gasto total de quase 25 bilhões de dólares, um aumento significativo quando comparado aos cerca de 14 bilhões de dólares alcançados em 1989.

Estudo detalhado realizado por Biasoto et al. (1998) sobre o gasto público em saúde no Brasil em 1995 chega às seguintes conclusões: "Nos últimos anos, as discussões em torno das questões do gasto público em saúde no Brasil têm se concentrado no financiamento. $\mathrm{O}$ cenário de incerteza, quanto às fontes de recursos, que se repete a cada ano, vem impedindo um exame mais detalhado da qualidade das ações de governo, contribuindo para o empobrecimento do debate. A análise, em caráter preliminar, das características do financiamento e do dispêndio governamental com a função, no Brasil, permite reunir as seguintes conclusões:

- O patamar do gasto no Brasil já é bastante elevado, da ordem de 3,5\% do PIB. O gasto por habitante/ano, de R\$ 146 em 1995, já alcança o volume considerado padrão por especialistas do setor.

- Gasto de Estados e municípios já supera o da União. A aplicação de recursos próprios/não vinculados aos repasses do Ministério da Saúde, da ordem de R \$ 10,4 bilhões anuais, é uma demonstração inequívoca do comprometimento de prefeitos e governadores com as ações de saúde.

- As aplicações são tipicamente de custeio. As despesas de "Pessoal", adicionadas a "Outras Correntes" concentram cerca de $82 \%$ do orçamento nacional, ou R\$ 21 bilhões. Os gastos em investimento são, ao contrário, muito baixos. Do valor total investido em 1995, de R \$ 446 milhões, cerca de $72 \%$ se concentra nos municípios, que vêm ampliando sua responsabilidade com a gestão da função saúde.

- Quanto aos programas de trabalho, destaca-se a rubrica "Assistência Médica e Sanitária”, na qual se registram os gastos na operação do sistema, com R $\$ 18,3$ bilhões ou $74 \%$ do total. Estados e municípios praticamente não participam das ações de prevenção, concentradas na União.

- Do valor total transferido pelo SUS em 1995, destaca-se a participação dos prestadores privados conveniados, que já equivale ao somatório dos repasses às unidades próprias de Estados e municípios. A rede privada predomina em quase todo o país, salvo em alguns Estados da Região Norte, onde a baixa renda e a densidade populacional ainda não garantem retorno para a atividade privada.

- As transferências do SUS têm um caráter regressivo, função dos critérios de repasse baseados na produção de serviços. As unidades mais pobres do Norte e do Nordeste recebem menos recursos por habitante do que o Sul/ Sudeste, onde a base econômica garante maior capacidade de geração de recursos fiscais próprios.

- As aplicações de Estados e municípios atingem cerca de $15 \%$ de sua receita disponível, mas em termos per capita existe uma profunda disparidade entre regiões pobres e ricas. O gasto subnacional por habitante é de R\$ 106 no Sul/Sudeste contra apenas R\$ 60 no Norte/Nordeste.

- É indiscutível o avanço da municipalização no país. Entretanto, ela vem ocorrendo de forma desigual, graças às disparidades de renda entre os municípios e também ao esquema de transferências do SUS, que não apresenta qualquer função de redistribuir recursos às unidades mais pobres. Cerca de $79 \%$ do gasto municipal em saúde e saneamento se concentra no Sul/Sudeste, onde reside $57 \%$ da população.

- Em termos médios, os municípios das regiões mais desenvolvidas respondem por quase dois terços dos gastos subnacionais em saúde e saneamento, contra apenas 40\% no Norte/Nordeste/Centro-Oeste. Destaca-se o avanço da municipalização nos Estados do Rio de Janeiro, São Paulo, Paraná e Rio Grande do Sul.

- Quanto ao gasto estadual, há grande variância até mesmo entre Estados da mesma região. Os governos estaduais financiam a maior parte dos gastos nos Estados do Acre, Roraima, Amapá, Tocantins, Piauí, Sergipe e Bahia.

- A divisão das despesas por categoria econômica e programa de trabalho, pelos governos estaduais das várias unidades da federação, tende a concentrar-se no custeio em geral e na assistência médica, respectivamente. Entretanto, os dados apontaram algumas distorções nas aplicações administrativas, especialmente nas unidades do Norte, CentroOeste e no Rio de Janeiro. Os investimentos apresentaram patamar bastante baixo, como era de se esperar, diante da crise dos Estados e do avanço da municipalização".

O Ipea, na sua avaliação dos "Gastos Sociais das três esferas de governo, 1995” (Fernandes et al., 1998), também chegou a resultados bastante similares ainda que com uma metodologia distinta de consolidação das informações. ${ }^{10}$

\section{DISTRIBUIÇÃO REGIONAL DO GASTO PÚBLICO PER CAPITA COM ATENÇÃO À SAÚDE}

A falta de eqüidade na alocação do gasto público, já citada, fica ainda mais evidente quando se compara o dispêndio setorial per capita em saúde de cada uma das três 


\begin{tabular}{lcccc}
\multicolumn{5}{c}{$\begin{array}{c}\text { TABELA 5 } \\
\text { Gasto Público per Capita em Saúde, por Instância } \\
\text { de Governo, segundo Região } \\
\text { Brasil - 1995 }\end{array}$} \\
\hline Região & União & Estados & Municípios & Total \\
\hline Total & $\mathbf{8 7 , 9}$ & $\mathbf{2 8 , 8}$ & $\mathbf{2 2 , 9}$ & $\mathbf{1 3 9 , 6}$ \\
Norte & 61,0 & 29,7 & 4,7 & 95,5 \\
Nordeste & 56,2 & 17,5 & 12,3 & 85,9 \\
Sudeste & 78,8 & 39,0 & 35,3 & 153,1 \\
Sul & 77,4 & 10,7 & 24,2 & 112,3 \\
Centro-Oeste & 80,8 & 52,6 & 4,8 & 138,1 \\
\hline
\end{tabular}

Fonte: Fundação IBGE/DECNA. Elaboração: Ipea/Dipos. In: NEPP (1999).

Nota: A média nacional é mais alta que as médias regionais por conter recursos não regionalizáveis.

instâncias de governo nas regiões brasileiras. Sabe-se que o gasto público é muito desigual entre as diferentes regiões e Estados, mas não é tão evidente, e as desigualdades se devem mais às diferenças nos aportes dos Estados e municípios: o dispêndio público total per capita varia entre R\$ 153,10 no Sudeste e R\$ 85,90 no Nordeste, ou seja, uma diferença de $\mathrm{R} \$ 67,20$, enquanto a variação do aporte federal para estas regiões é de apenas R\$21,60. Tal informação, ao demonstrar que a maior parte da desigualdade é explicada pelas diferenças nos aportes de recursos próprios de Estados e municípios (Tabela 5), acentua ainda mais o papel estratégico que a União terá de assumir para introduzir mecanismos de incentivo ao correto ordenamento da oferta de serviços para melhorar as condições de acesso.

Isso porque, por maior que seja o esforço redistributivo isolado da União, será mantido um certo grau de desigualdade na alocação de recursos públicos para a saúde, parte em decorrência das diferentes capacidades de arrecadação dos Estados e municípios das diferentes regiões brasileiras, e parte pela falta de incentivos para que as esferas subnacionais, autonomamente, alterem suas prioridades de inversão.

A necessidade desse papel de coordenação e de indução do MS fica mais clara quando se tomam as estimativas do gasto total no setor. As estimativas disponíveis, incluindo-se o gasto privado no segmento supletivo e no de desembolso direto, indicam cifras expressivas. Utilizandose a estimativa apresentada por Médici (1999) a partir de estudo de Mendes (1998) para o gasto privado, que contém informações relativamente compatíveis com as ante- riores, chega-se a 7\% do PIB com atenção à saúde e a um gasto per capita de US\$ 321,5 aproximadamente. Conseqüentemente, trata-se de um esforço de inversão bastante significativo, ainda que mal direcionado, no que diz respeito ao mix público/privado e gerenciado a partir de processos de hierarquização, regionalização e ordenamento da oferta de serviços com muitas brechas e falhas, proporcionando um esforço pouco efetivo. A correlação desse gasto com indicadores de resultado em saúde mostra que nossa situação sanitária e assistencial não é compatível com o esforço realizado na alocação de recursos.

\section{DESIGUALDADES NO ACESSO AOS SERVIÇOS}

As informações disponíveis permitem apontar alguns progressos no campo do acesso, ainda que continuem sendo verificadas, no Brasil, fortes disparidades na utilização de serviços, tanto entre regiões quanto entre segmentos sociais. Tomando-se um novo estudo de Travassos et al. (1998) verifica-se que: ${ }^{11}$ houve uma diminuição nos diferenciais de utilização entre as Regiões Nordeste e Sudeste e, na primeira, as melhorias relativas foram mais acentuadas. Os dados da PNSN mostraram uma maior taxa de utilização de serviços de saúde para os habitantes da Região Sudeste (19,49 por 100 habitantes) e menor para os habitantes da Região Nordeste (13,01 por 100 habitantes). A PPV, quase uma década depois, mostrou que as diferenças nas taxas de utilização entre Sudeste e Nordeste deixam de ser estatisticamente significativas, passando de 15,29 por 100 habitantes no Sudeste para 14,06 por 100 habitantes no Nordeste.

As taxas de utilização recalculadas para os grupos com e sem morbidade, de forma separada, mostraram diferenças significativas e desfavoráveis ao Nordeste. Em 1989, a taxa de utilização para a população com restrição de atividades foi de 46,39 por 100 habitantes no Nordeste e de 66,02 por 100 habitantes no Sudeste. Já em 1996/97 essas taxas passaram a ser de 59,57 por 100 habitantes e de 69,54 por 100 habitantes, respectivamente, para o Nordeste e para o Sudeste. Comparando a razão entre as taxas de utilização para a população com restrição, verificou-se uma diminuição de 17,6\% (1,42 em 1989 para 1,17 em 1996/97), o que mostra uma diminuição na desigualdade de acesso aos serviços de saúde entre as duas regiões. Dentro de cada região, analisando-se a taxa de utilização da população com restrição, verifica-se que a melhoria foi proporcionalmente maior na Região Nordeste (aumento de $28 \%$ ), do que na Sudeste (aumento de 5,3\%). 
QUADRO 1

Principais Desafios, Problemas, Soluções e Estratégias de Implementação Utilizadas na Reforma de Saúde Brasil, a partir de 1996

\begin{tabular}{|c|c|c|c|c|}
\hline Desafio & Problema & Solução & $\begin{array}{l}\text { Medidas } \\
\text { Implementadas }\end{array}$ & $\begin{array}{l}\text { Medidas em } \\
\text { Implementação }\end{array}$ \\
\hline Cobertura & $\begin{array}{l}10 \% \text { da população brasileira } \\
\text { (os mais pobres). } \\
\text { Os grupos mais ricos, que têm } \\
\text { planos de saúde, utilizam os } \\
\text { serviços do SUS sem recuperar } \\
\text { custos. }\end{array}$ & $\begin{array}{l}\text { Priorizar a atenção básica à saúde } \\
\text { de acordo com o perfil } \\
\text { epidemiológico dos mais pobres. } \\
\text { Iniciar experiências de } \\
\text { ressarcimento dos usuários do } \\
\text { SUS e cobranças dos que têm } \\
\text { recursos para pagar. }\end{array}$ & $\begin{array}{l}\text { Plano de Assistência Básica } \\
\text { (PAB); Farmácia Básica do SUS } \\
\text { (PAF); Programa de Combate às } \\
\text { Carências Nutricionais (PCCN); } \\
\text { Programa Ampliado de } \\
\text { Imunizações (PAI) e Programa } \\
\text { de Atenção à Saúde da Mulher } \\
\text { (PAISM). Aprovação pelo } \\
\text { Conselho Nacional de Medicina } \\
\text { Supletiva (Consu) de resolução } \\
\text { para recuperar custos dos } \\
\text { serviços do SUS utilizados por } \\
\text { beneficiários de planos privados } \\
\text { de saúde. }\end{array}$ & $\begin{array}{l}\text { Estudos específicos para } \\
\text { melhorar os critérios de } \\
\text { focalização, distribuição dos } \\
\text { recursos e definição de ações } \\
\text { prioritárias nestes programas. } \\
\text { Iniciar a experiência de } \\
\text { recuperação de custos e } \\
\text { estendê-la a outras atividades. }\end{array}$ \\
\hline Financiamento & $\begin{array}{l}\text { Instabilidade das fontes de } \\
\text { financiamento. } \\
\text { Ineficiência no uso dos recursos. }\end{array}$ & $\begin{array}{l}\text { Definir fontes exclusivas de } \\
\text { recursos para o setor, bem como o } \\
\text { comprometimento de maiores } \\
\text { parcelas dos orçamentos dos } \\
\text { Estados e municípios. Priorizar a } \\
\text { atenção básica de acordo com o } \\
\text { perfil epidemiológico. }\end{array}$ & $\begin{array}{l}\text { Aprovação da CPMF como fonte } \\
\text { exclusiva de recursos para o } \\
\text { setor. } \\
\text { Aprovação do PAB. }\end{array}$ & $\begin{array}{l}\text { Estudos que permitam definir } \\
\text { um novo modelo de financia- } \\
\text { mento do sistema. Estudos que } \\
\text { permitam definir os itens que } \\
\text { deverão compor o PAB, de } \\
\text { acordo com as prioridades } \\
\text { dadas pela carga de enfermida- } \\
\text { de. Implantação do } \\
\text { "Cartão SUS". }\end{array}$ \\
\hline \multirow[t]{2}{*}{ Eqüidade } & $\begin{array}{l}\text { Assimetria de informação entre } \\
\text { usuários ricos e pobres. } \\
\text { Deseconomias de aglomeração, } \\
\text { beneficiando os mais ricos. }\end{array}$ & $\begin{array}{l}\text { Incentivar o uso de estratégias que } \\
\text { busquem ativamente a proteção } \\
\text { dos usuários mais pobres. } \\
\text { Priorizar a oferta pública para os } \\
\text { mais pobres nos bairros mais } \\
\text { distantes. }\end{array}$ & $\begin{array}{l}\text { Implementação progressiva dos } \\
\text { programas de Agentes } \\
\text { Comunitários de Saúde (PACS) } \\
\text { e Saúde da Família (PSF). } \\
\text { Ampliação da Oferta de Serviços } \\
\text { nas regiões mais carentes - } \\
\text { implantação do PACS e do PSF. }\end{array}$ & \\
\hline & $\begin{array}{l}\text { Seleção adversa, segundo o valor } \\
\text { do procedimento, beneficiando a } \\
\text { alta complexidade. } \\
\text { Sistemas regidos pela oferta } \\
\text { beneficiam os que têm mais } \\
\text { informação. }\end{array}$ & $\begin{array}{l}\text { Incentivar melhor remuneração } \\
\text { para os serviços de maior custo } \\
\text { efetivo. } \\
\text { Estabelecer sistemas de } \\
\text { capacitação com subsídios de } \\
\text { demanda diferenciados por } \\
\text { capacidade de pagamento. }\end{array}$ & Implantação do PAB. & $\begin{array}{l}\text { Definição do valor dos } \\
\text { procedimentos incentivados } \\
\text { pelo PAB, no nível dos Estados } \\
\text { e municípios. } \\
\text { Recuperação dos custos } \\
\text { para o SUS dos usuários dos } \\
\text { planos privados de saúde. }\end{array}$ \\
\hline Descentralização & $\begin{array}{l}\text { Transferências negociadas } \\
\text { beneficiam os municípios com } \\
\text { melhor capacidade de oferta de } \\
\text { serviços. } \\
\text { Rigidez do modelo impede } \\
\text { soluções mais adequadas no } \\
\text { nível local. }\end{array}$ & $\begin{array}{l}\text { Usar transferências automáticas, } \\
\text { em bases per capita. } \\
\text { Flexibilizar o uso de diferentes } \\
\text { mecanismos de gestão e torná-los } \\
\text { independentes dos recursos } \\
\text { transferidos. }\end{array}$ & $\begin{array}{l}\text { Implantação do PAB, } \\
\text { PAF e PCCN. } \\
\text { Implantação dos mecanismos de } \\
\text { controle e avaliação da gestão } \\
\text { municipal do PAB. }\end{array}$ & $\begin{array}{l}\text { Transferências automáticas de } \\
\text { recursos para o PAF e o PCCN. }\end{array}$ \\
\hline
\end{tabular}


QUADRO 1

Principais Desafios, Problemas, Soluções e Estratégias de Implementação Utilizadas na Reforma de Saúde Brasil, a partir de 1996

\begin{tabular}{|c|c|c|c|c|}
\hline Desafio & Problema & Solução & $\begin{array}{l}\text { Medidas } \\
\text { Implementadas }\end{array}$ & $\begin{array}{l}\text { Medidas em } \\
\text { Implementação }\end{array}$ \\
\hline \multirow[t]{4}{*}{ Gestão } & \multirow{3}{*}{$\begin{array}{l}\text { Estabelecimentos de saúde } \\
\text { prestam serviços de baixa } \\
\text { qualidade. } \\
\text { Insuficiente capacidade técnica } \\
\text { dos Recursos Humanos. } \\
\text { Fraudes propiciam forte } \\
\text { desperdício dos recursos gastos } \\
\text { em assistência médica. } \\
\text { Falta de autonomia de gestão das } \\
\text { unidades de saúde. }\end{array}$} & $\begin{array}{l}\text { Implementar um processo de } \\
\text { acreditação e licenciamento dos } \\
\text { estabelecimentos de saúde. } \\
\text { Implantação de processos de } \\
\text { certificação e recertificação } \\
\text { periódica de profissionais de } \\
\text { nível superior. }\end{array}$ & $\begin{array}{l}\text { Existem algumas experiências } \\
\text { estaduais que vêm sendo } \\
\text { observadas pelo Ministério da } \\
\text { Saúde, como as do Rio Grande } \\
\text { do Sul, São Paulo e Rio } \\
\text { de Janeiro. }\end{array}$ & \\
\hline & & $\begin{array}{l}\text { Capacitação de profissionais de } \\
\text { nível médio nos hospitais e postos } \\
\text { de saúde. Fim do Sistema de AlH } \\
\text { no âmbito federal. }\end{array}$ & $\begin{array}{l}\text { O PACS e o PCF têm programas } \\
\text { especiais de capacitação de } \\
\text { profissionais de saúde nos } \\
\text { Estados e municípios. }\end{array}$ & $\begin{array}{l}\text { O programa de formação do } \\
\text { auxiliar de enfermagem } \\
\text { (Profae) vai desenvolver } \\
\text { programas específicos. }\end{array}$ \\
\hline & & $\begin{array}{l}\text { Criação de mecanismos de } \\
\text { controle e avaliação nos Estados } \\
\text { e municípios. } \\
\text { Tornar independente a gestão dos } \\
\text { estabelecimentos públicos de } \\
\text { saúde. }\end{array}$ & $\begin{array}{l}\text { O PAB inicia o processo. } \\
\text { Existem algumas experiências } \\
\text { de contratos de gestão e } \\
\text { organizações sociais em } \\
\text { estabelecimentos públicos } \\
\text { de saúde. }\end{array}$ & \\
\hline & Falta de regulamentação do setor. & $\begin{array}{l}\text { Estabelecimento de regras para a } \\
\text { regulação dos planos privados de } \\
\text { saúde. } \\
\text { Regulação dos processos de } \\
\text { gestão do SUS nos Estados e } \\
\text { municípios. }\end{array}$ & $\begin{array}{l}\text { No início de } 1998 \text { foi aprovada a } \\
\text { Lei de Regulamentação dos } \\
\text { Planos provados de saúde, } \\
\text { criando o Conselho de Medicina } \\
\text { Supletiva (Consu). } \\
\text { O PAB inicia o processo. }\end{array}$ & $\begin{array}{l}\text { O Ministério da Saúde está } \\
\text { preparando, através do } \\
\text { Departamento de Medicina } \\
\text { Supletiva, a legislação } \\
\text { complementar para a } \\
\text { implementação das medidas } \\
\text { de regulação dos planos } \\
\text { privados de saúde. }\end{array}$ \\
\hline
\end{tabular}

A taxa de utilização das pessoas sem restrição de atividades também mostra diferenças desfavoráveis ao Nordeste, embora menos significativas. A análise dos dados da PNSN, ao final dos 80, mostra uma taxa de utilização de 10,23 por 100 habitantes no Nordeste e de 14,55 por 100 habitantes no Sudeste. Já as informações da PPV, quase dez anos depois, indicam que as taxas baixaram para 9,04 por 100 habitantes no Nordeste e para 11,32 por 100 habitantes no Sudeste. A razão de utilização entre Sudeste e Nordeste, por sua vez, baixou de 1,42 para 1,25 no período 1989-1996/97. Isso implicou uma queda de quase $12 \%$, ainda que nas duas regiões as taxas de utilização para as pessoas sem restrição de atividades tenham diminuído em algum período.
As oportunidades de acesso aos serviços para os indivíduos mais pobres diminuem nas duas regiões. Utilizando-se a renda como proxy das condições sociais, verificam-se as piores oportunidades de utilização de serviços por parte de indivíduos pertencentes ao primeiro tercil de renda em relação aos indivíduos situados no terceiro tercil. No Nordeste, em 1989, a oportunidade de acesso era 52\% menor para o primeiro tercil. Oito anos mais tarde esse diferencial baixou para 37\%. No Sudeste, as oportunidades do primeiro tercil na utilização de serviços de saúde eram $40 \%$ e $35 \%$ menores do que dos indivíduos do terceiro tercil, respectivamente, em 1989 e 1996/97. Notese que no Nordeste, ainda assim, houve uma melhoria no acesso da população de menor renda. 
No que diz respeito à utilização de serviços, propriamente dita, o estudo mostra que:

- há maior participação relativa da utilização de postos e centros de saúde no Nordeste, em relação à maior participação de clínicas e consultórios privados na Região Sudeste;

- há aumento expressivo de hospitais como locus de consumo de serviços de saúde nas duas regiões, particularmente no Nordeste;

- as pessoas de maior renda utilizam mais consultórios particulares e clínicas, enquanto as de menor renda, principalmente postos e centros de saúde;

- em ambas as regiões, os indivíduos de renda mais alta utilizam proporcionalmente mais serviços ambulatoriais, enquanto os serviços hospitalares tendem a aumentar com a diminuição da renda.

Estudo de Campino et al. (1998), também analisado por Piola em NEPP (1999), utilizando os dados da PPV, fornece outras informações importantes sobre a utilização e a demanda por serviços, segundo pessoas em diferentes estratos de renda.

Com relação à percepção do estado de saúde, cerca de $81 \%$ da população avalia seu estado de saúde como excelente, muito bom ou bom. A percepção positiva é mais forte quanto maior o nível de renda, pois no primeiro quintil $76,2 \%$ dos indivíduos possuem essa auto-avaliação, enquanto no último ela atinge $87,5 \%$.

Curiosamente, a existência de problemas crônicos de saúde (15,4\% no total da população) não apresenta grande variação entre os estratos de renda: $12,30 \%$ no primeiro e $15,4 \%$ no último quintil.

As diferenças começam a se tornar mais evidentes quando a pesquisa verifica a utilização de acompanhamento médico: enquanto $54,7 \%$ dos indivíduos mais pobres têm acompanhamento médico em decorrência de problema crônico de saúde, no estrato mais alto $82,9 \%$ dos indivíduos declaram ter acesso a esse tipo de serviço.

Nota-se, entretanto, que o local onde é realizado esse acompanhamento é predominantemente a rede pública, para todos os estratos de renda, com exceção do último.

Os mais ricos também fazem exames periódicos com maior freqüência: a realização de exames periódicos em decorrência do problema crônico de saúde é progressivamente maior, conforme o estrato de renda: $60,9 \%$ dos indivíduos do primeiro quintil e $82,5 \%$ do último.

A procura por atendimento médico nos últimos 30 dias também é progressivamente maior à medida que a renda cresce: $47,2 \%$ dos indivíduos no estrato de mais baixa renda buscaram algum tipo de atendimento médico, percentual que se eleva para $68,9 \%$ entre os indivíduos do último quintil de renda.

A procura por atendimento derivada de outro motivo, ${ }^{12}$ exceto doença crônica, também é maior entre os indivíduos mais ricos: $13,5 \%$ dos indivíduos de maior renda procuraram atendimento, enquanto entre os mais pobres o percentual encontrado foi de 7\%. É relevante notar que entre os motivos da procura, a realização de check-up, portanto uma atividade típica de prevenção, corresponde a $28,5 \%$ entre os mais ricos e a apenas $13,9 \%$ entre os mais pobres.

\section{MEDIDAS GOVERNAMENTAIS RECENTES: UMA VISÃO SINTÉTICA}

As questões indicadas nos itens anteriores, que examinam diferentes aspectos da realidade do atendimento à saúde no Brasil após uma década de implantação do SUS, mostram que é preciso avançar na implementação de alterações estruturais nas formas de organização, gestão, regulação, controle e avaliação da oferta de serviços. Algumas medidas já estão sendo tomadas e vários desafios sendo enfrentados, sem que entretanto possa se visualizar uma agenda completa e consistente de intervenção do Poder Público. As medidas governamentais recentes foram sintetizadas em Médici (1999) e são reproduzidas no quadro a seguir. Note-se que as medidas em estágios diferenciados de implementação e com resultados ainda pouco avaliados, dado o caráter recente da maioria delas, aproximam-se dos dois eixos principais de mudança já identificados na análise da literatura internacional realizada na primeira seção deste trabalho. Em outras palavras, no plano mais geral, a reforma brasileira busca focalizar as questões do financiamento no nível macro e da gestão tanto no nível macro quanto microorganizacional.

Alguns problemas estruturais persistem. Dentre eles se destacam:

- ausência de um sistema de planejamento e controle da oferta de serviços eficaz e que proporcione informações estratégicas de apoio à decisão alocativa no nível central, regional e inter-regional;

- falta de mecanismos institucionais eficazes para a criação e sustentação de bases consensuais mínimas para impulsionar um processo renovado de contratualização entre provedores, financiadores e reguladores (inexistência de relações de confiança); 
- forte tendência de veto à contratualização por parte dos atores sociais que devem ser protagonistas das mudanças;

- dificuldades para o estabelecimento de um "pagador único" e de formas de participação mais eqüitativas no financiamento do sistema (universalidade versus gratuidade);

- problemas nas relações entre níveis de governo: indefinição do papel da esfera estadual; dificuldades nas relações horizontais no nível municipal.

\section{DILEMAS E PERSPECTIVAS DO SUS}

A despeito da complexidade dos problemas de ordenamento e acesso, tal como demonstrado anteriormente neste artigo, é possível identificar elementos propulsores à implementação de alterações para superar os obstáculos identificados. Entre outros, cabe lembrar: o perfil do processo de descentralização, em curso, é favorável em grande parte de seus aspectos; existem recursos para investimento que, se utilizados como vetores de reorientação da oferta via Reforsus, auxiliaram na obtenção de maior eficácia da rede de serviços; formas de organização da administração pública brasileira, principalmente pós-Plano Diretor da Reforma Administrativa e no âmbito de um novo governo com perfil desenvolvimentista, podem garantir a flexibilidade e autonomia necessárias para o funcionamento das redes prestadoras de serviço, permitindo maior controle da oferta; formato dos mecanismos de financiamento setorial pode tornar-se proativo, por exemplo, através da adoção de vinculações institucionais associadas ao estabelecimento de pisos básicos em todos os níveis de atendimento, auxiliando uma sistemática de contratualização que efetivamente seja aderente às necessidades e prioridades diferenciadas de atendimento, hierarquizadas por ações de planejamento, avaliação e controle; reestruturação, em curso, da Atenção Primária abre boas possibilidades para o estabelecimento de uma porta de entrada mais resolutiva e eficaz; já existem várias inovações organizacionais e gerenciais em andamento e coerentes com uma mecânica de contratualização que vise aumentar os níveis de acesso, cobertura e ordenamento das ações e serviços.

\section{NOTAS}

1. Para uma competente e sintética revisão das lições internacionais acerca dos experimentos nacionais de reforma setorial, em curso des- de meados dos anos 80 vide Ham (1998). Esta introdução baseia-se numa livre interpretação de várias idéias contidas nesse livro.

2. Artigo 196, constante do Capítulo da Saúde da Constituição Federal da República Federativa do Brasil.

3. Sobre as características da política de atenção à saúde no Brasil, até os anos 80, vide entre outros Braga e Góes de Paula (1981), Oliveira e Fleury (1985), Silva (1984) e Médici (1999).

4. Trata-se aqui das clínicas e hospitais privados, muitas vezes voltados, originalmente, ao atendimento de determinados grupos étnicos - judeus, sírio-libaneses, alemães, espanhóis, etc. -, mas que constituem hoje a rede hospitalar privada mais complexa (os hospitais de cinco estrelas) atendendo outros clientes privados (pessoas físicas ou jurídicas) e seguros médicos de mais alto padrão, dada a sua excelência e mantendo na maioria das vezes um atendimento gratuito, como parte da manutenção de sua condição jurídica de entidades filantrópicas. Isso possibilita vantagens fiscais e tributárias significativas, entre outras.

5. Médici (1999) analisando os dados da PNAD 1986, comenta que o pagamento também se verificou nas famílias de maior renda, embora por razões diametralmente opostas: neste caso as razões declaradas foram a baixa qualidade dos serviços públicos e conseqüentemente uma maior preferência pelos serviços oferecidos pelo segmento privado autônomo.

6. No caso da farmácia, os autores alertam que os dados indicam ser esse um padrão comum a todas as classes de renda, indicando que a automedicação ou a medicação realizada pelo balconista do estabelecimento era corrente e disseminada no Brasil. Para fins da argumentação deste artigo, sugere-se que para os segmentos mais pobres essa era e continua sendo muitas vezes a única alternativa e por isso a alternativa preferencial, o que não é verdade para os segmentos de renda mais alta.

7. Este número foi obtido subtraindo-se do total da população brasileira as pessoas atendidas pelo setor de medicina supletiva.

8. A pesquisa foi de caráter nacional, realizada no período de 12 a 17 de fevereiro de 1998 , tendo como universo a população de idade igual ou superior a 16 anos. Foram realizadas 2 mil entrevistas pessoais domiciliares, selecionadas a partir de amostra elaborada por cotas proporcionais: sexo, idade, atividade e localização geográfica. Essa amostra representa cerca de 106 milhões de habitantes adultos e 40 milhões de domicílios.

9. Não cabe, no âmbito deste trabalho, analisar as modificações no processo de financiamento setorial e que determinaram as flutuações e a turbulência acima apontadas, especialmente quando a diversificação prevista em 1988 não foi suficiente para, dada a crise financeira da Previdência Social, evitar o desfinanciamento quase completo da política, corrigida de forma provisória posteriormente. Esse fato determinou uma forte deterioração das relações entre prestadores e financiadores e a alteração do perfil e da forma de funcionamento do setor privado e do próprio setor público na área hospitalar. Maiores detalhes em Médici (1999), Barros, Piola e Vianna (1996), entre outros.

10. Para uma discussão detalhada acerca das diferenças metodológicas entre esses dois estudos vide o trabalho de Sérgio Piola em NEPP (1999).

11. Esse trabalho analisa as desigualdades geográficas e sociais na utilização dos serviços de saúde no Brasil com base nos dados da Pesquisa Nacional de Saúde e Nutrição (PNSN), realizada em 1989 e da Pesquisa sobre Padrões de Vida (PPV), de 1996/97, ambas realizadas pela Fundação Instituto Brasileiro de Geografia e Estatística (IBGE). As duas pesquisas têm abrangência desigual: a PNSN incorporou as cinco regiões geográficas do país enquanto a PPV cobriu somente as Regiões Nordeste e Sudeste. A comparação, a despeito das limitações decorrentes dessas diferenças, é relevante para os propósitos deste trabalho. Nesse estudo, os autores analisam as variações nas taxas de utilização dos serviços de saú- 
de, padronizadas por idade e sexo, calculando-se as taxas gerais e para os grupos com e sem morbidade. Considerou-se grupo sem morbidade aquele em que não existe referência a qualquer restrição de atividades em decorrência dessa particular situação.

12. Foram pesquisados os seguintes motivos, nessa categoria: acidente ou lesão, problema odontológico, check-up, parto, obtenção de atestado, tratamento de reabilitação, pré-natal, vacinação e outros.

\section{REFERÊNCIAS BIBLIOGRÁFICAS}

BANCO MUNDIAL. Relatório sobre o desenvolvimento mundial 1993: investimento em saúde. Rio de Janeiro: FGV, 1993.

BARROS, M.E.; PIOLA, S.F.; VIANNA, S.M. Política de Saúde no Brasil: diagnóstico e perspectivas. Brasília: Ipea, 1996. (Texto para Discussão, n.401).

BARROS, R.P.; MENDONÇA, R.; NERI, M. An evaluation of the measurement of income and expenditure in household surveys: POF versus PNAD. Anais... Encontro Brasileiro de Econometria. XVIII, 1995, p.105-129.

BAYER, G.F.; LEIS, H. Saúde enquanto questão politicamente intermediada. Serviço Social \& Sociedade, v.22, p.103-125, 1986.

BERMUDEZ, J. Remédio: saúde ou indústria? A produção de medicamentos no Brasil. Rio de Janeiro: Relume Dumará, 1992.

BIASOtTO, G. et al. Notas acerca do gasto público em saúde no Brasil - Exercício de 1995. 1998. Mimeografado.

BRAGA, J.C.; GÓES DE PAULA, S. Saúde e previdência: estudos de política social. Rio de Janeiro: Cebes; Hucitec, 1981.

BRASIL. Ministério da Saúde, Secretaria de Assistência à Saúde, Secretaria Executiva. Avaliação da gestão da assistência ambulatorial e hospitalar do SUS. Supervisão - 1997. Brasília, DF: 1997.

CAMPINO, A.C.C. (Coord.). et al. Equity in health in LAC-Brazil, 1998. Mimeografado.

CASTRO, P.F. de; MAGALHÃES, L.C. de. Recebimento e dispêndio das familias brasileiras: evidências recentes da Pesquisa de Orçamentos Familiares (POF) - 1995/1996. Brasília, DF: Ipea, 1998 (Texto para Discussão, n.614).

DRAIBE, S.M. A politica brasileira de combate à pobreza. In: VELLOSO, J.P. dos R. (Coord.). X Fórum Nacional: o Brasil e o Mundo no Limiar do Novo Século. Rio de Janeiro: José Olympio, v.2, p.299-328, 1998.

FERNANDES, M.A. et al. Gasto social das três esferas de governo, 1995. Brasília, DF: Ipea/Dipos, 1998 (Texto para Discussão, n.598).

FUNDO DAS NAÇÕES UNIDAS PARA A POPULAÇÃO. A situação da população mundial 1998: as novas gerações. Nova York: FNUAP, 1998.

HAM, C. (Ed.). Health care reform: Learning from international experience. Buckingham, Philadelphia: Open Univ., 1998.

IBOPE. Promoção da saúde: pesquisa de opinião pública. São Paulo: IBOPE, [19--]. (Pesquisa realizada sob encomenda do Conass/ FNS).

KLEIN, R. Why Britain is reorganizing its national health service yet again. Health Affairs, v.17, n.4, p.111-125, 1998.

LEVCOVITZ, E. Transição X consolidação: o dilema estratégico da construção do SUS 1997. Tese (Doutorado em Saúde Coletiva) Instituto de Medicina Social da Uerj. São Paulo, 1997.
LONDOÑO, J.L.; FRENK, J. Pluralismo estructurado: Hacia un modelo innovador para la reforma de los sistemas de salud en América Latina. Washington, D.C.: BID, 1997. (Serie de Documentos de Trabajo, 353).

MAXWELL, R.J. Financing health care: lessons from abroad. British Medical Journal, n.296, p.1.423-1.426, 1988.

MÉDICI, A.C. Los gastos de salud en las famílias en Brasil: algunas evidencias de su caracter regressivo. Washington: BID, 2001.

História e políticas de saúde no Brasil: um balanço do processo de descentralização. 1999. Tese (Doutorado em História Econômica) - Departamento de História Econômica da USP. São Paulo, 1999.

$$
\text { . O SUS e a política "Hood Robin" de Saúde, } 1998 .
$$
Mimeografado.

Perfil da saúde no Brasil. Brasília, DF: Ipea, 1997. (Texto para Discussão, n.472).

MENDES, E.V. O sistema de serviços de saúde no Brasil. Brasília, DF: OPS, 1998. Mimeografado.

NEPP. Projeto O setor saúde e o complexo da saúde no Brasil. In: Formação do sistema de saúde brasileiro: balanço e perspectivas estratégicas. 1999. Mimeografado.

OCKÉ REIS, C.O. O setor privado "autônomo": um caso de política. Seminário: A Regulamentação dos Planos e Seguros Privados no Brasil. In: VIANA, A.L.; REIS, C.O. (Coords.). Estudos em Saúde Coletiva. Rio de Janeiro: IMS/Uerj, n.152, p.5-18, 1997.

OLIVEIRA, F. de. O surgimento do antivalor. Capital, força de trabalho e fundo público. Novos Estudos Cebrap, v.22, p.8-22, 1988.

OLIVEIRA, J.; FLEURY, S. (Im)previdência social: 60 anos de história da previdência no Brasil. Rio de Janeiro: Vozes, 1985.

PIOLA, S.F. Financiamento como elemento para construção da eqüidade. Síntese de palestra proferida em 16 de novembro de 1998 no XIV Congresso Nacional de Secretários Municipais de Saúde, Goiânia.

PORTO, S.M. Eqüidade na distribuição dos recursos em saúde: uma contribuição para o caso brasileiro. ago. 1977. Tese (Doutorado) - Fundação Oswaldo Cruz, Escola Nacional de Saúde Pública. Rio de Janeiro, 1977.

PROGRAMA DAS NAÇÕES UNIDAS PARA O DESENVOLVIMENTO, INSTITUTO DE PESQUISA ECONÔMICA APLICADA. Relatório sobre o desenvolvimento humano no Brasil 1996. Rio de Janeiro: Ipea; Brasília, DF: PNUD, 1996.

SILVA, P.L.B. Atenção à saúde como política governamental. 1984 Dissertação (Mestrado) - IFCM/Unicamp. Campinas, 1984.

Limites e obstáculos à reforma do Estado no Brasil: a experiência da previdência social na nova república. 1992, 216 p. Tese (Doutorado em Ciência Política) - Faculdade de Filosofia, Ciências Humanas da USP. São Paulo, 1992.

THE WORLD BANK. Brazil: fiscal adjustment and social spending the case of education health in four Brazilian State. Washington, DC: The World Bank, 1998. (Report n. BR 17.763).

TRAVASSOS, C. et al. Desigualdades geográficas e sociais na utilização de serviços de saúde no Brasil. Rio de Janeiro: [199-]. Mimeografado.

TRAVASSOS, C.; FERNANDES, C.; PEREZ, M. Desigualdades sociais no acesso e na utilização de serviços de saúde no Brasil. Rio de Janeiro: 1989. Mimeografado.

TRAVASSOS, C. et al. Desigualdades geográficas e sociais na utilização de serviços de saúde no Brasil. In: ALMEIDA, C. (Coord.). Projeto $A$ reforma sanitária brasileira: em busca da eqüidade. 
Financiado pela Organização Panamericana de Saúde, 1998. Mimeografado.

UNITED NATIONS DEVELOPMENT PROGRAMME. Human Development Report 1998. New York: UNDP, 1998.

VIANA, A.L. d'Á.; DAL POZ, M.R. Estudo sobre o processo de reforma em saúde no Brasil. In: PROGRAMA DE INVESTIGACIÓN SOBRE REFORMAS SOCIALES EN EDUCACIÓN Y SALUD EN AMERICA LATINA Y EL CARIBE, 1998.

VIANNA, S.M.; PIOLA, S.F.; REIS, C.O.O. Gratuidade no SUS: controvérsia em torno do co-pagamento. Brasília, DF: Ipea, 1998. (Texto para Discussão, n.587).
VIANNA, S.M.; PIOLA, S.F. Descentralização e gestão do gasto público. In: Compêndio de documentos: Taller sobre evaluación de la géstión del gasto público en salud. Cepal/BID/Ipea, 1999, p.105-140.

VOX POPULI MERCADO E OPINIÃO. Usuários Inamps/Segurado INPS. [São Paulo]: Vox Populi, 1987. (Relatório).

Pedro Luiz Barros Silva: Professor do Instituto de Economia e Coordenador do Núcleo de Estudos de Políticas Públicas da Universidade Estadual de Campinas (pbar@nepp.unicamp.br). 